\title{
A Comparative Evaluation of Stress Distribution by Three Different Designs of Prefabricated Metal Posts on Endodontically Treated Permanent Maxillary Central Incisor: A Three-dimensional Finite Element Study
}

\author{
${ }^{1}$ Ganesh Pandurang Mengal, ${ }^{2} J y o t i ~ N a d g e r e, ~{ }^{3}$ Sabita M Ram, ${ }^{4}$ Naisargi Shah
}

\begin{abstract}
Purpose of the study: This study intends to evaluate and compare the stress distribution by three designs of prefabricated metal posts, parallel post (EG post), parallel post with coronal flare (i-post) and a tapered post (Filpost) in endodontically treated permanent maxillary central incisor. This study will help the dentists to choose the post that would generate the least stress in endodontically treated teeth.
\end{abstract}

Procedure: Three-dimensional (3D) finite element models were developed. The physical models include composite resin core material, dentin, endodontic post, luting cement and guttapercha. They were subjected to compressive load of $100 \mathrm{~N}$ at $135^{\circ}$ angle with respect to longitudinal axis of tooth, above the level of cingulum, simulating the load condition in oral cavity and the effects of three posts on stress distribution, in endodontically treated maxillary central incisor was evaluated.

Results: Stress distribution was found to be better in the models having parallel post and parallel post with the coronal flare. Coronal flare has an added advantage of better fit in the root canal.

Conclusion: It was found that the stresses in maxillary central incisor with the parallel post with coronal flare were well distributed.

Keywords: Finite element analysis, Post and core, Post design, Stress distribution.

How to cite this article: Mengal GP, Nadgere J, Ram SM, Shah N. A Comparative Evaluation of Stress Distribution by Three Different Designs of Prefabricated Metal Posts on Endodontically Treated Permanent Maxillary Central Incisor: A Three-dimensional Finite Element Study. J Contemp Dent 2015;5(3):123-130.

Source of support: Nil

Conflict of interest: None

\section{INTRODUCTION}

Preservation of tooth structure, restoration of function, esthetics and harmonious occlusion are the prime

\footnotetext{
${ }^{1}$ Practitioner, ${ }^{2,4}$ Professor, ${ }^{3}$ Professor, Head and Dean

${ }^{1-4}$ Department of Prosthodontics, MGM Dental College and Hospital, Navi Mumbai, Maharashtra, India

Corresponding Author: Ganesh Pandurang Mengal, Practitioner Department of Prosthodontics, MGM Dental College and Hospital Navi Mumbai, Maharashtra, India, Phone: 9028546321, e-mail: dr.ganeshmengal@gmail.com
}

objectives of prosthodontics. ${ }^{1}$ Grossly carious teeth involving pulp require endodontic treatment which is the most widely used technique in present day to save the teeth whenever possible. ${ }^{2}$ The prognosis of the endodontically treated teeth depends not only on the success of the endodontic treatment but also on the type of reconstruction. ${ }^{3}$ Endodontically treated teeth having insufficient coronal structure need to be restored with post and core to replace the missing component of tooth structure. ${ }^{1}$ Prefabricated posts are most commonly used to restore the teeth. As the adaptation of the prefabricated posts to the root canal may not conform as accurately as custom made posts, understanding the biomechanical factors, such as design of the post that affect the ability of the post to fit more accurately with minimum movement and least thickness of cement is very important.

The stress analysis of post and core systems can be done either by photoelastic analysis or finite element analysis. Photoelastic analysis has certain drawbacks, such as difficulty to exactly duplicate the material properties. Also results can only be approximated. Finite element analysis can be carried out on two-dimensional (2D) models or three-dimensional (3D) models. Twodimensional analysis has its limitations as stresses can only be observed in 2D. Three-dimensional models are able to simulate the condition in 3D so that more authentic results can be achieved. Its greatest advantage is that the results are reproducible and authentic.

This finite element study was planned to evaluate and compare the stress distribution on 3D models of endodontically treated maxillary central incisor with three types of prefabricated metal posts having parallel sides, tapered sides and a parallel sided post with coronal flare.

\section{MATERIALS AND METHODS}

The methodology developed for this study was based on the creation of finite element models.

I. Construction of the models as follows:

1. Three-dimensional finite element modeling of Permanent maxillary central incisor:

Three-dimensional models endodontically treated permanent maxillary central incisors were 
developed in the CAD software Pro/Engineer Wildfire 4.0. Extracted permanent maxillary central incisor was used as a reference (Fig. 1).

2. Three-dimensional finite element modeling of three types of commercially available posts:

Three-dimensional finite element models of three types of commercially available posts, parallel post (EG post) (Fig. 2), parallel post with coronal flair (i-post) (Fig. 3) and tapered post (Filpost) (Fig. 4) were modeled by taking reference of posts and observing the fine design of the posts under the stereomicroscope. The schematic diagrams of the three posts were drawn with the help of measurements of the posts and stereomicroscopic images.

3. Assembling of 3D finite element model of endodontically treated maxillary central incisor with the three types of posts.

The root canal and the post space modeled in the 3D model of maxillary central incisor would be similar to dimensions of the posts used in other three models with

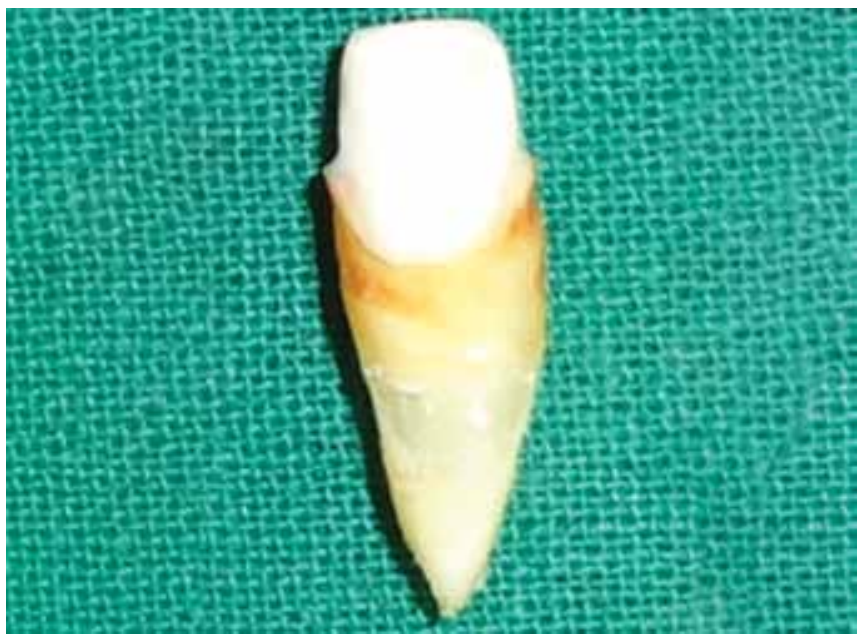

Fig. 1: Extracted permanent maxillary central incisor prepared to receive a full coverage crown

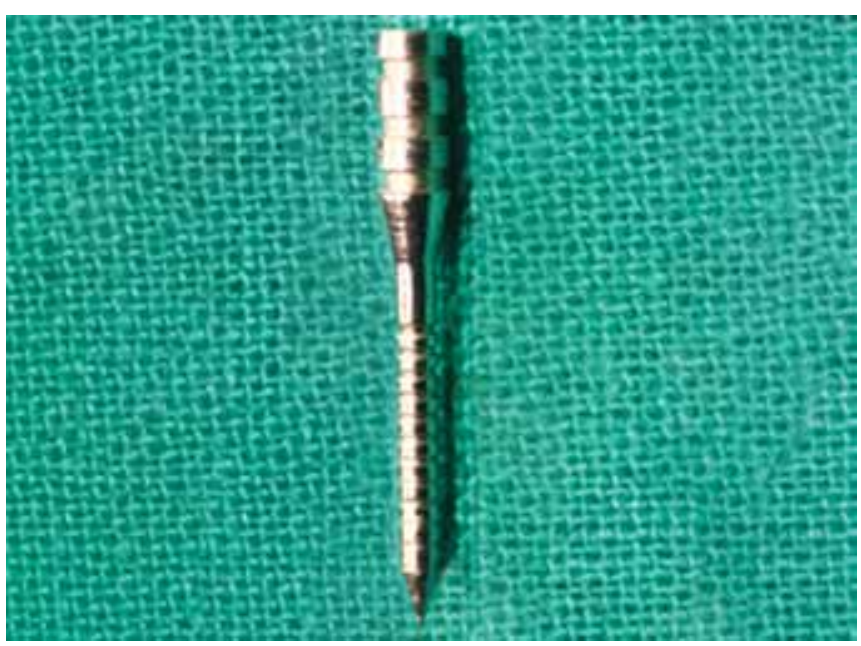

Fig. 3: i-post gutta-percha filling the root canal. In the post space, three types of posts were inserted.

The final four assembled are as follows:

- Model I: Endodontically treated maxillary central incisor prepared to receive a full coverage crown without any post with composite rein core (Fig. 5).

- Model II: Endodontically treated maxillary central incisor prepared to receive a full coverage crown with parallel post and composite resin core (Fig. 6).

- Model III: Endodontically treated maxillary central incisor prepared to receive a full coverage crown with coronally flared parallel post and composite resin core. (Fig. 7).

- Model IV: Endodontically treated maxillary central incisor prepared to receive a full coverage crown with tapered post and composite resin core (Fig. 8).

II. Meshing the models: A 3D finite element mesh was created using the ANSYS preprocessor. Care was taken to concentrate the mesh pattern in the region like cervical portion of the models where we want to

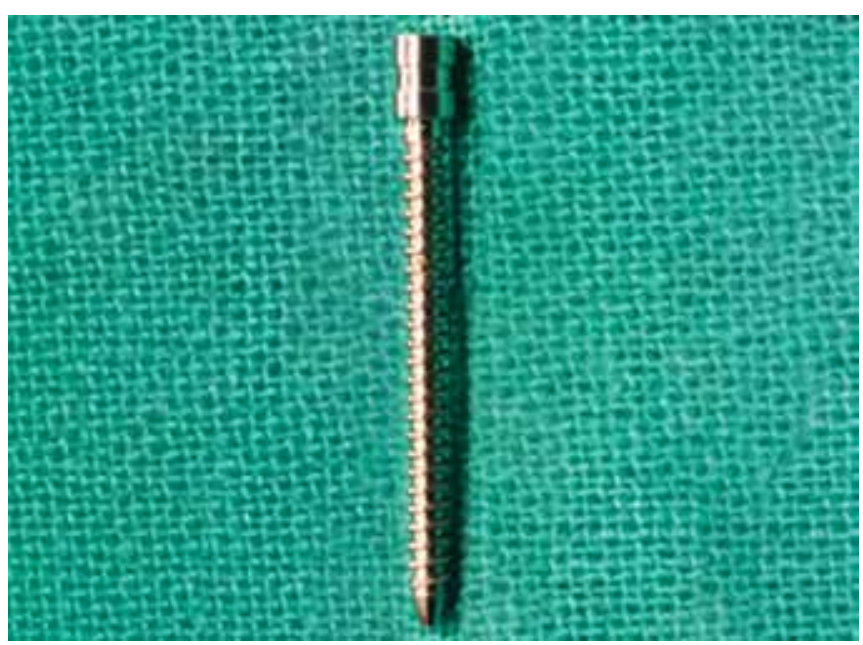

Fig. 2: EG post

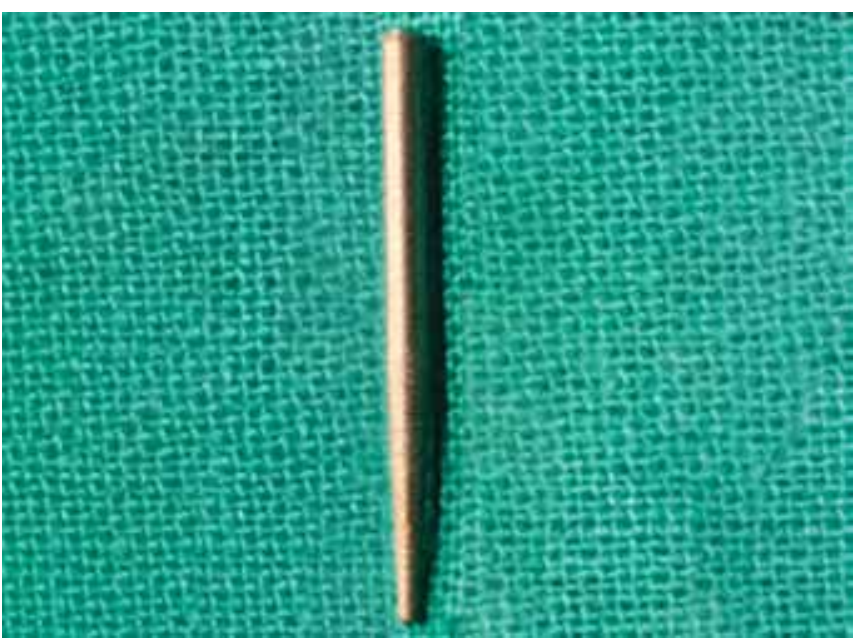

Fig. 4: Filpost 


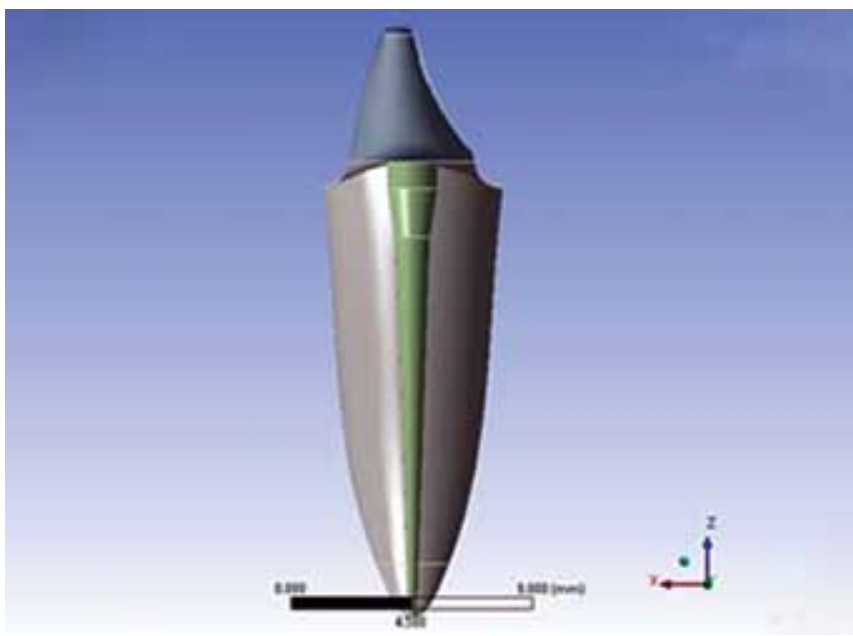

Fig. 5: Three-dimensional finite element model of endodontically treated permanent maxillary central incisor

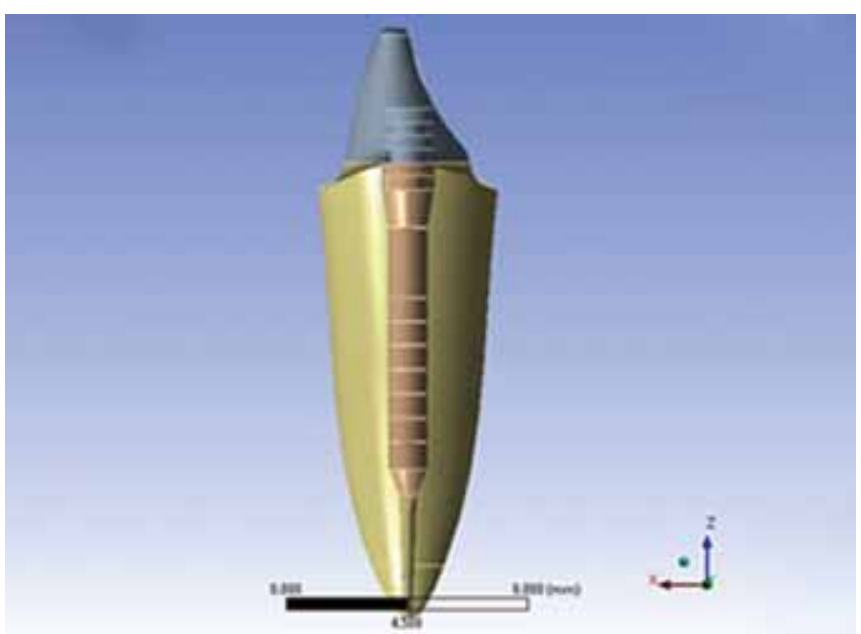

Fig. 7: Three-dimensional finite element model of endodontically treated permanent maxillary central incisor with parallel post with coronal flare

study the stress distribution. For this reason, different types of elements were selected which were wellsuited for modeling irregular meshes. Each node had freedom to move in the $x, y$ and $z$ planes. The elements were constructed to be as accurate as possible within the limitations of software. Types of elements used in the models were solid186:3-D 20-Node structural solid, solid187:3-D 10-Node tetrahedral structural solid, shell181: 4-Node structural shell. The total number of elements present in model I were 65603, in model II 191870, in model III 122951 and in model IV were 631015 (Figs 9 to 12).

III. Assigning material properties: The material properties, i.e., Young's Modulus and Poisson's ratio for the different materials used in this study, were taken from literature (Table 1) and assigned to the different parts of the models (Fig. 13).

IV. Applying the boundary conditions: Boundary conditions were applied on the outer layer of nodes on the root portion of all the maxillary central incisor models,

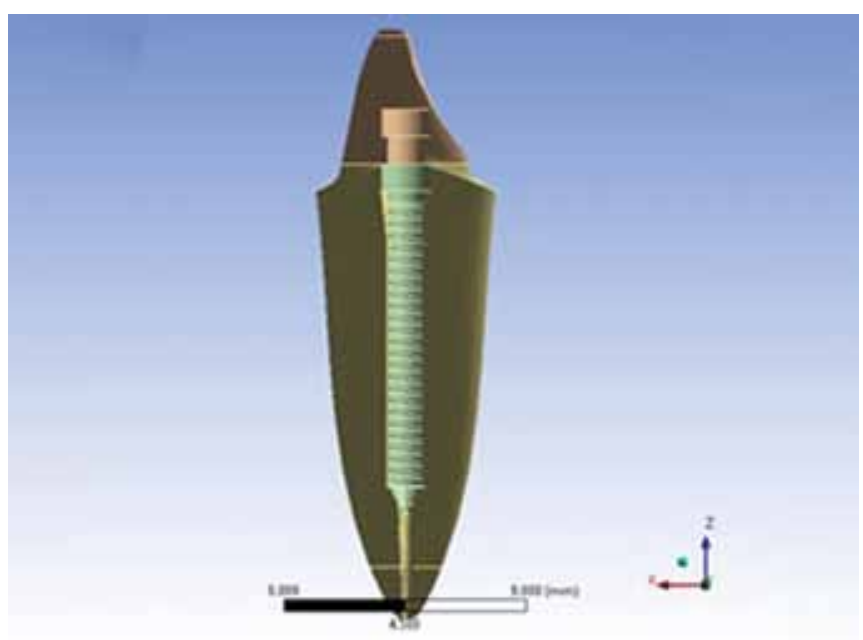

Fig. 6: Three-dimensional finite element model of endodontically treated permanent maxillary central incisor with parallel post

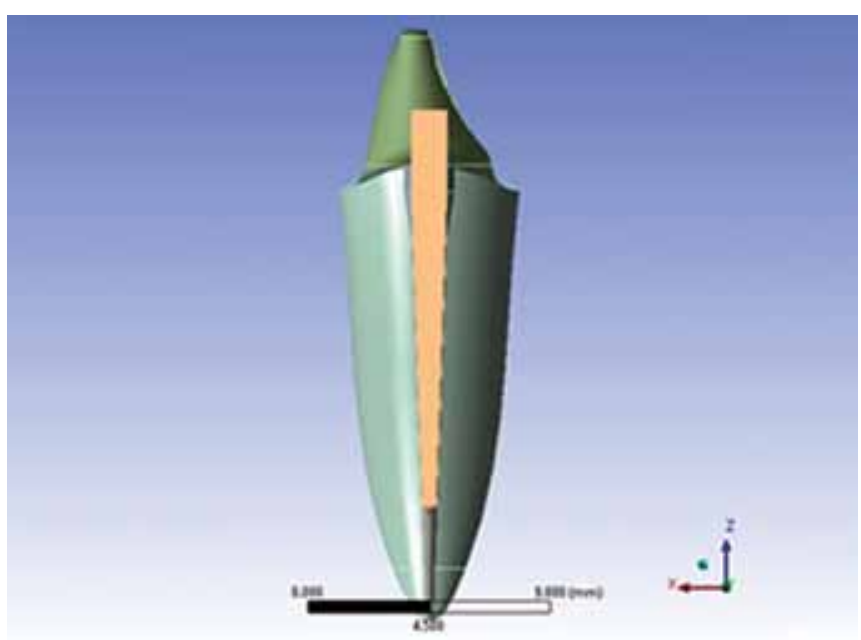

Fig. 8: Three-dimensional finite element model of endodontically treated permanent maxillary central incisor with tapered post

Table 1: Material properties

\begin{tabular}{lll}
\hline Material & $\begin{array}{l}\text { Young's modulus } \\
\text { (in GPA) }\end{array}$ & Poisson's ratio \\
\hline Dentin & 18.6 & 0.31 \\
Composite resin & 15.5 & 0.30 \\
Gutta-percha & 0.00069 & 0.45 \\
Zinc phosphate cement & 22.4 & 0.25 \\
Stainless steel & 210 & 0.30 \\
Titanium & 120 & 0.30 \\
\hline
\end{tabular}

so that the models were fixed in all 3D without any translation. This was done to simulate the conditions in the bone.

V. Loading of the models: All four models were subjected to compressive load of $100 \mathrm{~N}$ at $135^{\circ}$ angle with respect to longitudinal axis of tooth, at the level of cingulum, simulating the load condition in class I occlusion in the oral cavity ${ }^{4}$ (Figs 14 to 17).

Once the geometry is converted into the finite element form, it is to be solved by ANSYS software. The results for the stress were interpreted from color coded images 


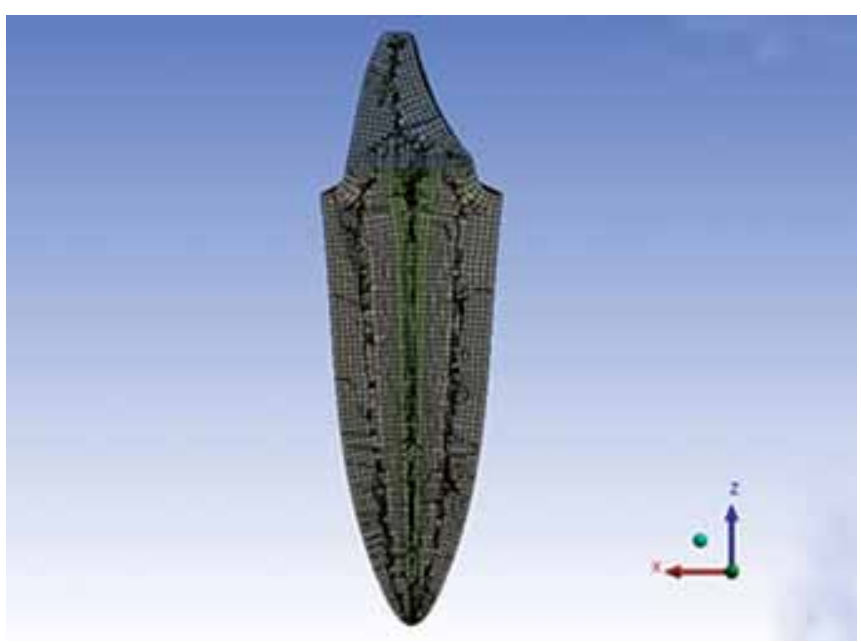

Fig. 9: Meshing of model I: Three-dimensional finite element model of endodontically treated maxillary central incisor prepared to receive a full coverage crown without post with composite resin core

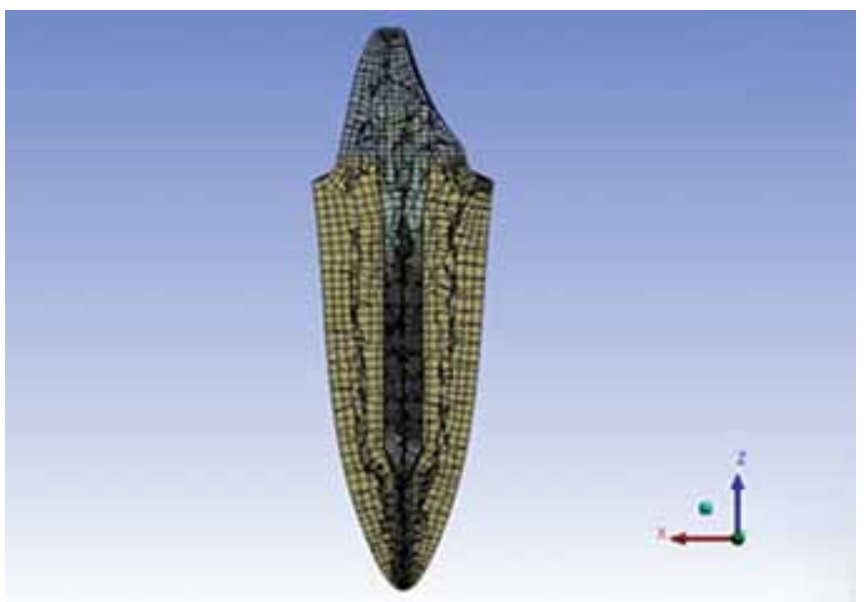

Fig. 11: Meshing of model III: Three-dimensional finite element model of endodontically treated maxillary central incisor prepared to receive a full coverage crown with parallel post with coronal flare and composite resin core

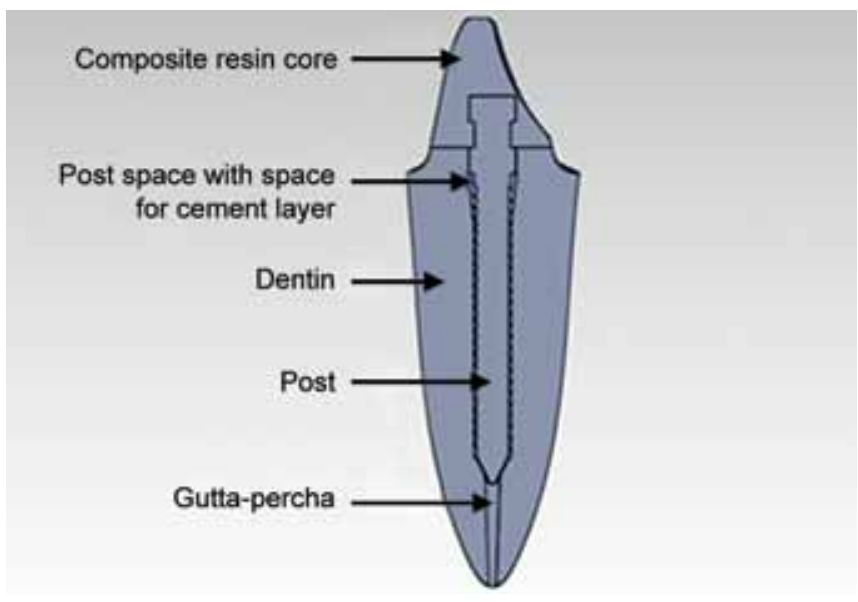

Fig. 13: Components of the meshed models

seen in the 3D finite element models. Red color represents maximum stress values. This was followed in descending order by orange, yellow, light green, dark green, light

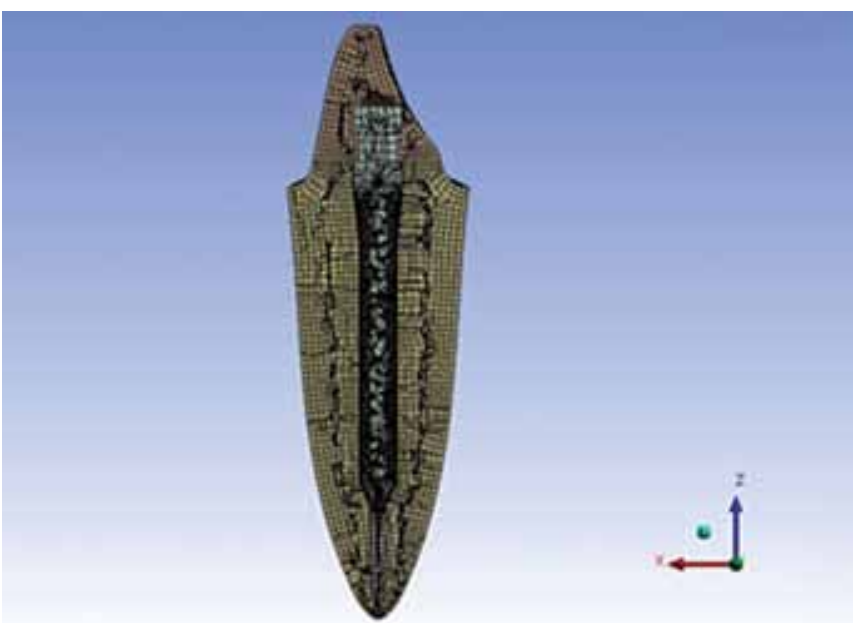

Fig. 10: Meshing of model II: Three-dimensional finite element model of endodontically treated maxillary central incisor prepared to receive a full coverage crown with parallel post and composite resin core

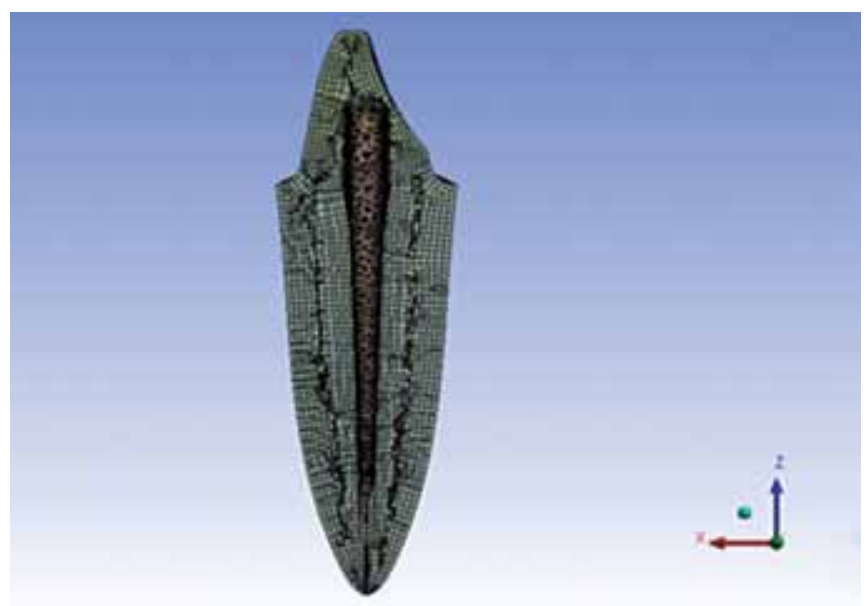

Fig. 12: Meshing of model IV: Three-dimensional finite element model of endodontically treated maxillary central incisor prepared to receive a full coverage crown with tapered post and composite resin core

green, light blue and dark blue. Dark blue represents the area of least stress values.

\section{RESULTS AND DISCUSSION}

The present study evaluates the stress distribution in three different designs of prefabricated metal posts (Fig. 18) (Tables 2 and Graph 1). Various methods like photoelastic analysis, ${ }^{5-10} 2 \mathrm{D}$ finite element analysis ${ }^{11-17}$ or $3 \mathrm{D}$ finite element analysis ${ }^{18-21}$ can be used to evaluate the stress distribution in endodontically treated teeth. In 3D finite element analysis, 3D models are able to simulate the condition in $3 \mathrm{D}$ so that more authentic results can be achieved.

When comparing the maximum amount of stresses of model I, model II, model III and model IV, negligible difference in the values of stresses was observed in the composite resin core. However, distribution of stresses 


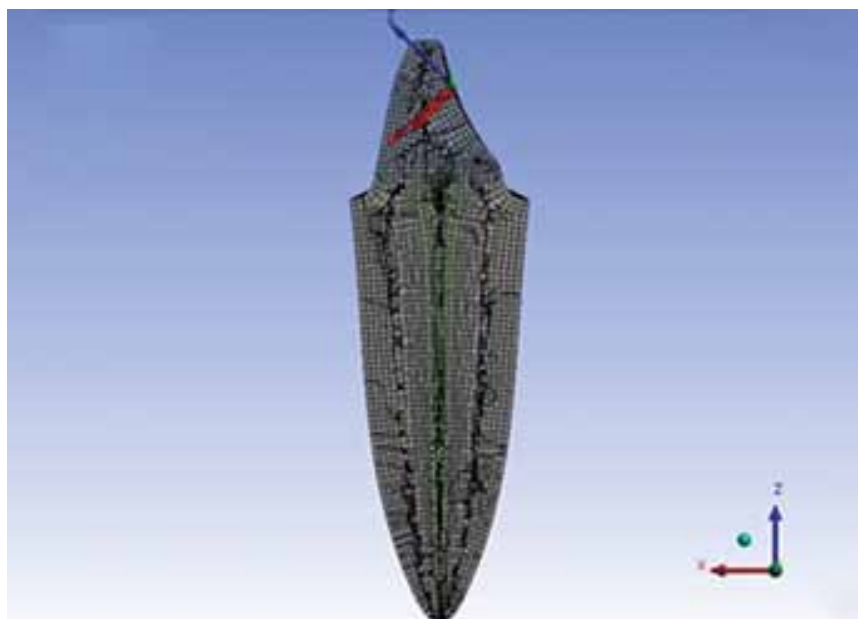

Fig. 14: Loading of model I: Three-dimensional finite element model of endodontically treated maxillary central incisor prepared to receive a full coverage crown without post with composite resin core

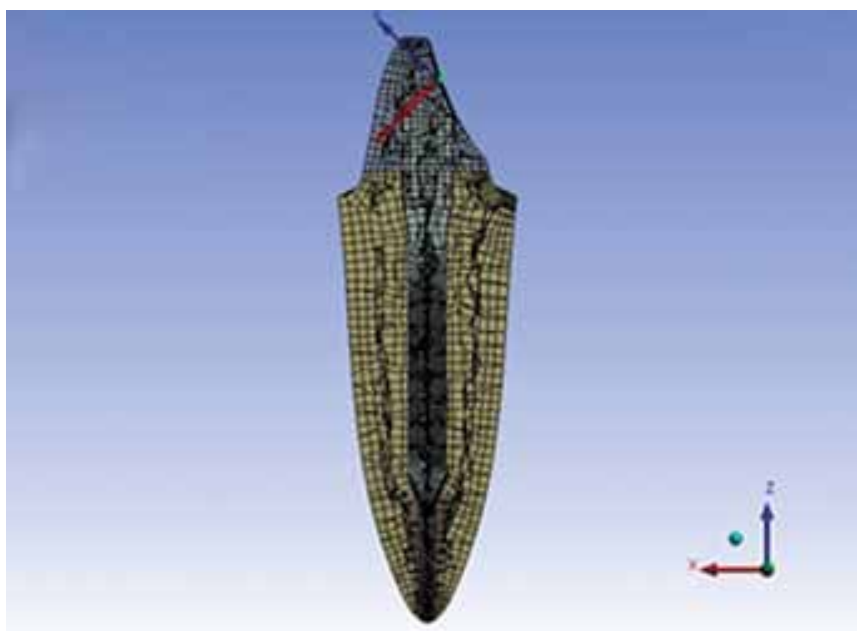

Fig. 16: Loading of model III: Three-dimensional finite element model of endodontically treated maxillary central incisor prepared to receive a full coverage crown with parallel post with coronal flare and composite resin core

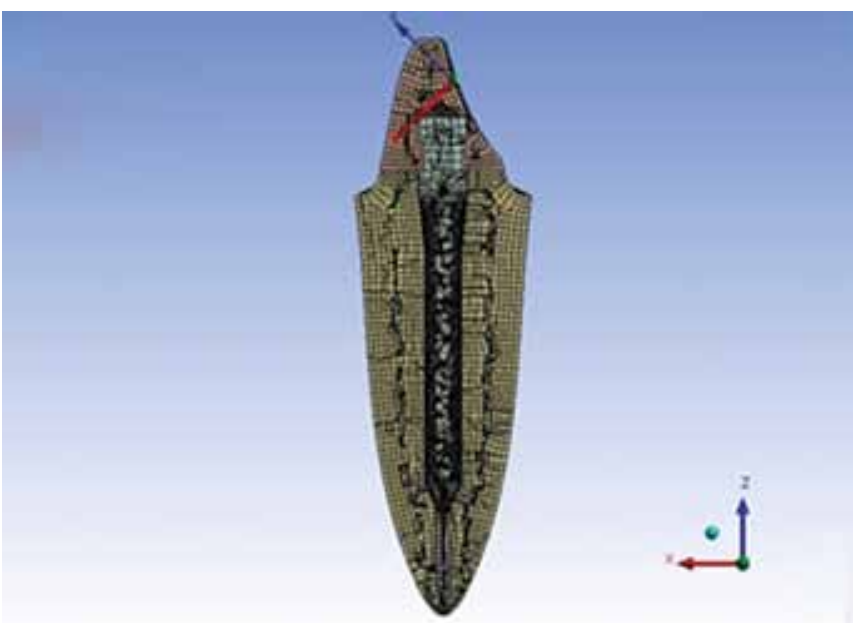

Fig. 15: Loading of model II: Three-dimensional finite element model of endodontically treated maxillary central incisor prepared to receive a full coverage crown with parallel post and composite resin core

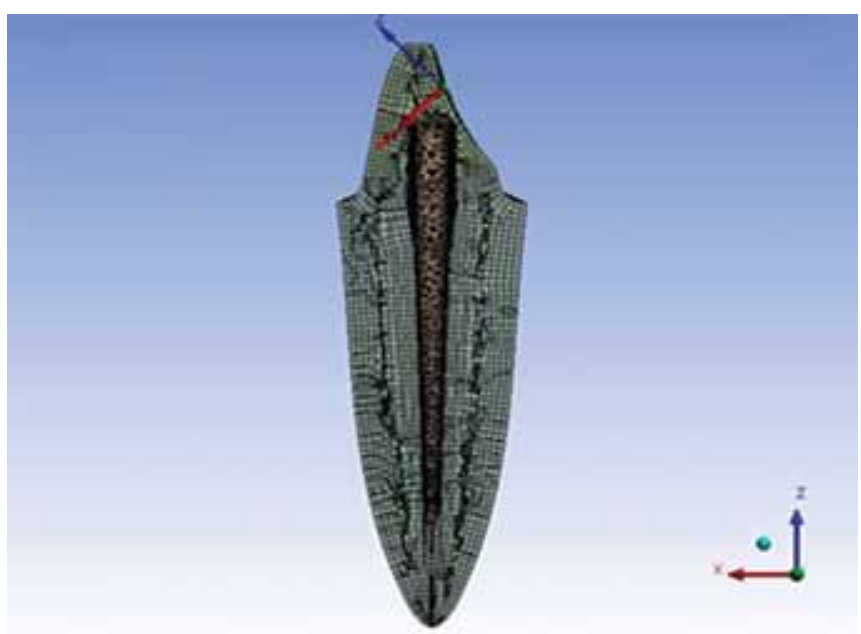

Fig. 17: Loading of model IV: Three-dimensional finite element model of endodontically treated maxillary central incisor prepared to receive a full coverage crown with tapered post and composite resin core

Table 2: Comparison of stress distribution of the four models of endodontically treated maxillary central incisor (in MPa)

\begin{tabular}{lllllll}
\hline Models & Composite core & Dentin & Gutta-percha & Post & Cement layer & Model \\
\hline I & $0.20083-68.69$ & $0.00031567-34.557$ & $4.2147 \mathrm{e}^{-5}-10.315$ & - & - & $4.2147 \mathrm{e}^{-5}-68.69$ \\
II & $0.25876-68.827$ & $0.006415-31.505$ & $3.1809 \mathrm{e}^{-7}-0.85012 \mathrm{e}^{-3}$ & $0.055003-$ & $0.0070828-$ & $3.1809 \mathrm{e}^{-7}-85.427$ \\
& & & & 85.427 & 18.986 & \\
III & $0.18675-68.696$ & $0.0024379-29.884$ & $1.6816 \mathrm{e}^{-8}-9.3351 \mathrm{e}^{-5}$ & $\begin{array}{l}0.0001392- \\
4.8586 \mathrm{e}^{-5}-\end{array}$ & $1.6816 \mathrm{e}^{-8}-98.157$ \\
& & & & 98.157 & 14.361 & \\
IV & $0.2436-70.281$ & $0.00076425-32.227$ & $9.5055 \mathrm{e}^{-9}-1.6239 \mathrm{e}^{-5}$ & $0.017082-$ & $0.0033536-$ & $9.5055 \mathrm{e}^{-9}-127.02$ \\
& & & & 127.02 & 21.98 & \\
\hline
\end{tabular}

varied with model I showing even distribution of stresses in composite resin core. Model II and model III showed even stress distribution on labial side, however, in model IV more isolated stress concentration was seen on mid labial side.

The distribution of stresses in dentin in all the models was observed to be concentrated at cemento-enamel junction. However, the amount of stresses in model III was least. This may have been due to the coronal flare of the post, coming in contact with dentin over a large area at the coronal flare of the root canal, therefore, stress distributed over a larger area. The largest value of stress in dentin was seen in model I. As no post was placed in the tooth, all the stresses were taken by the dentin. In model IV stresses in dentin were much higher as compared to model II and model III, however, less than in model I. This may have been due to the titanium material of the post which has less modulus of elasticity, 

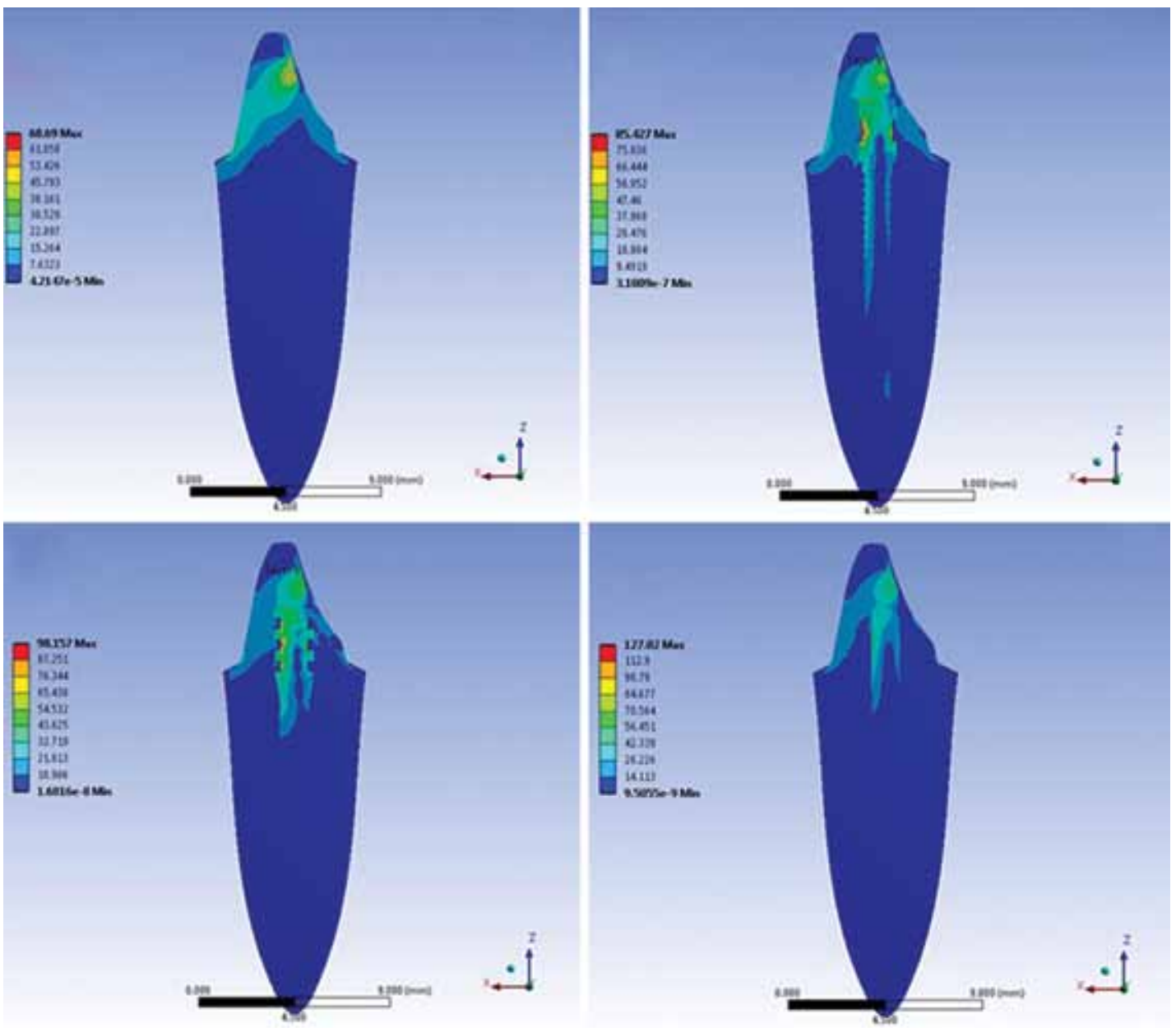

Fig. 18: Comparison of stress distribution of the four models of endodontically treated maxillary central incisor

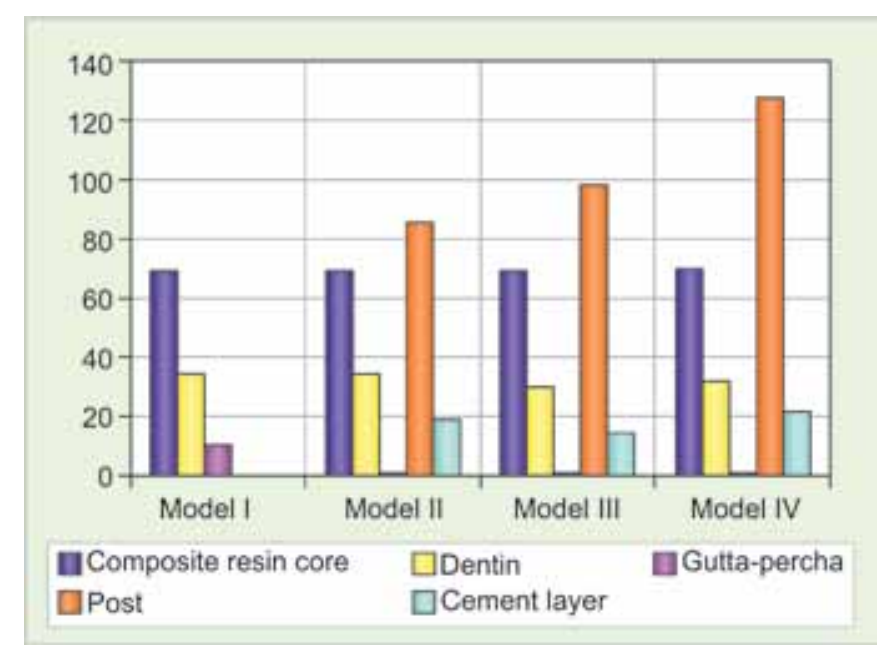

Graph 1: Maximum stresses observed in the four models of endodontically treated maxillary central incisor (in MPa)

therefore, it would transmit more forces on the dentin. Stresses seen in dentin in model II were more than model III. Due to parallel design of post in model III, more stresses were directed to dentin, whereas in model III least stresses were directed to the dentin. It could be due to the design of the post in model III, which fits in the coronal flare of the root canal and helps to distribute the stresses on the dentin.
The stresses in post of model II, model III and model IV showed varied patterns. The value of stress in model IV was shown to be the most and least in model II. The parallel post with coronal flare in model III showed stress value between the model II and model IV. However, the distribution of stresses in model IV were concentrated more in the coronal one third of the post, as it was a tapered post. In model III, the distribution was more even extending a little beyond coronal one third of the post. This may have been due to the design of the post. In model II, the distribution was beyond the half the length of the parallel post and also on the apical portion on palatal side. This could be correlated to the parallel design of the post.

Maximum stress values in cement layer were seen in model IV, with tapered post design followed by with model II with parallel post design. In model III with i-post least stresses were seen in the cement layer which is a point of advantage using the post with the coronal flare as it fits in the root canal snugly with thin cement layer and it does not allow any movement in the root canal preventing stresses in the cement layer. However, model IV with tapered post may have thicker cement layer and may have movement in coronal half of the root canal and, therefore, maximum stress value in cement layer. 
Maximum stress value in gutta-percha was observed in model I and very negligible amount of stresses were observed in gutta-percha in model II, model III and model IV. This may be because of absence of post in model I. In other three models, the stresses were mainly taken up by the posts, dentin, and cement layer. The distribution of stresses in gutta-percha was mainly in coronal one-third in model I and in model II, model III and model IV near the tip of the post.

From the stress analysis study, it can be concluded that in endodontically treated tooth with composite resin core without post showed the most stresses in the guttapercha and composite core build-up. That with tapered post due to the lack of adaptation of the post in the root canal, may have space between the post and coronal flare of the root canal and, therefore, more stresses in cement may lead to decementation of the post. The parallel post though adapts in canal may still show lack of adaptation in the coronal half of the root canal. Whereas i-post fits in the root canal more accurately in coronal half also due to its inherent design of the post with coronal flare.

\section{CONCLUSION}

- In the model without post with composite resin core, stresses were mainly observed in composite resin core. Stresses were also distributed in dentin in cemento-enamel junction area and coronal one-third gutta-percha.

- In the model with parallel post, stresses were observed mainly distributed over a large area in composite resin core and half length of the post. However, stresses were also observed in dentin in cemento-enamel junction area, in cement layer and gutta-percha.

- In the model with parallel post with coronal flare, stresses were distributed over a large area in composite resin core and in coronal one-third of the post. In dentin stresses were distributed in cemento-enamel junction, in cement layer and in guttta-percha.

- In the model with tapered post, concentrated stresses were observed in the composite resin core on buccal side and in coronal one-fourth of the post on buccal side. In dentin stress concentration was seen in the cemento-enamel junction area. Stresses were also seen in cement layer and gutta-percha. Maximum stresses were observed in model having tapered post in composite resin core, dentin, post and cement layer.

- In all the models, stresses were mainly distributed in the composite resin core. Maximum stress values in composite resin core were almost similar in all models. In all the models stresses in dentin were mainly concentrated in cemento-enamel junction area. Maximum stresses in dentin were present in model I and minimum in model III. Stresses in post were distributed in coronal half of EG post, in coronal one-third in i-post and coronal one-fourth of Filpost. Maximum amount of stresses in cement layer were present in Filpost and minimum in EG post. Stresses in cement layer were mainly distributed in cervical area in all the models. Maximum amount of stresses were present in model IV and minimum in model III. Stresses present in gutta-percha were maximum in model I, which were distributed in cervical one-third of gutta-percha. In all other models very minimal amount of stresses were present, which were mainly apical to the post.

- The distribution of stresses in the model with EG post and model with i-post were almost similar. However, the adaptation of i-post was better and comparative maximum stress values in the dentin were least in the model with i-post.

\section{REFERENCES}

1. Christensen GJ. Posts and cores: state of the art. JADA 1998; 129(1):96-97.

2. Peroz I, Blankenstein F, Klaus PL, Naumann M. Restoring endodontically treated teeth with posts and cores: a review. Quintessence Int 2005;36(9):737-746.

3. Trushkowsky RD. Esthetic and functional consideration in restoring endodontically treated teeth. Dent Clin N Am 2011;55(2):403-410.

4. Steiner CC. The use of cephalometrics as an aid to planning and assessing orthodontic treatment. Am J Orthod 1960; 46(10):721-735.

5. Henry PJ. Photoelastic analysis of post core restorations. Aus Den J 1977;22(3):157-159.

6. Mattison GD, Fraunhofer JA. Angulation loading effects on cast-gold endodontic posts: a photoelastic stress analysis. J Prosthet Dent 1983;51(4):509-514.

7. Assif D, Oren E, Marshak BL, Aviv I. Photoelastic analysis of stress transfer by endodontically treated teeth to the supporting structure using different restorative techniques. J Prosthet Dent 1989;61(5):535-543.

8. Hunter AJ, Feiglin B, Williams JF. Effects of post placement on endodontically treated teeth. J Prosthet Dent 1989;62(2): 166-172.

9. Burns DA, Krause WR, Douglas HB, Burns DR. Stress distribution surrounding endodontic posts. J Prosthet Dent 1990;64(4):412-418.

10. Rolf KC, Parker MW, Pellew GB. Stress analysis of five prefabricated endodontic dowel designs: a photoelastic study. J Oper Dent 1992;17(3):86-92.

11. Davy D, Dilley G, Krejci R. Determination of stress patterns in root-filled teeth incorporating various dowel Designs. J Dent Res 1981;60(7):1301-1310.

12. Peters MR, Poort HW, Farah JW, Craig RG. Stress analysis of a tooth restored with a post and core. J Dent Rest 1983;62(6): 760-763. 
13. Eskitascioglu G, Belli S, Kalkan M. Evaluation of two post core systems using two different methods (fracture strength test and a finite elemental stress analysis). J Endodont 2002;28(9): 229-233.

14. Albuquerque R, Polleto L, Fontana R, Cimini Jr. Stress analysis of an upper central incisor restored with different posts. J Oral Rehabil 2003;30(9):936-943.

15. Asmussen E, Peutzfeldt E, Sahafi A. Finite element analysis of stresses in endodontically treated dowel-restored teeth. J Prosthet Dent 2005;94(4):321-329.

16. Ulbrich N, Franco A, Zielak P, Mathias P. The stress evaluation of root posts using the finite element analysis. RSBO 2011; 8(2):189-193.

17. Sethuraman $R$. The effect of three post and core systems on the stress distribution in endodontically treated teeth: a two dimensional finite element analysis. J Adv Dent Res 2011;2(1):41-49.
18. Adanir N, Belli S. Stress Analysis of a maxillary central incisor restored with different posts. Eur J Dent 2007;1(2): 67-71.

19. Sorrentino R, Aversa R, Ferro V, Auriemma T, Zarone F, Ferrari M, Apicella A. Three-dimensional finite element analysis of strain and stress distributions in endodontically treated maxillary central incisors restored with different post, core and crown materials. Dent Mat 2007;(23): 983-993.

20. Silva N, Castro C, Santos P, Silca G, Campos R, Soares P, Soares C. Influence of different post designs and composition on stress distribution in maxillary central incisor: finite element analysis. Ind J Den Res 2009;20(2):153-158.

21. Bessone L, Fernandez BE. Evaluation of different post systems: finite element method. Int J Odontostomat 2010; 4(3):229-236. 